\title{
Clearance of dying autophagic cells of different origin by professional and non-professional phagocytes
}

\author{
G Petrovski ${ }^{1}$, G Zahuczky ${ }^{1}, K_{\text {Katona }}{ }^{1}$, G Vereb ${ }^{1}$, W Martinet ${ }^{2}$, Z Nemes ${ }^{1}$, W Bursch ${ }^{3}$ and L Fésüs ${ }^{\star, 1}$
}

MCF-7 cells undergo autophagic death upon tamoxifen treatment. Plated on non-adhesive substratum these cells died by anoikis while inducing autophagy as revealed by monodansylcadaverine staining, elevated light-chain-3 expression and electron microscopy. Both de novo and anoikis-derived autophagic dying cells were engulfed by human macrophages and MCF-7 cells. Inhibition of autophagy by 3-methyladenine abolished engulfment of cells dying through de novo autophagy, but not those dying through anoikis. Blocking exposure of phosphatidylserine (PS) on both dying cell types inhibited phagocytosis by MCF-7 but not by macrophages. Gene expression profiling showed that though both types of phagocytes expressed full repertoire of the PS recognition and signaling pathway, macrophages could evolve during engulfment of de novo autophagic cells the potential of calreticulin-mediated processes as well. Our data suggest that cells dying through autophagy and those committing anoikis with autophagy may engage in overlapping but distinct sets of clearance mechanisms in professional and non-professional phagocytes.

Cell Death and Differentiation (2007) 14, 1117-1128. doi:10.1038/sj.cdd.4402112; published online 16 March 2007

In mammalian organisms various forms of cell death may occur. Apoptosis or type I 'programmed cell death' (PCD), upon activation, proceeds via 'extrinsic' (death receptor activation) and 'intrinsic' (mitochondrial) pathways, both converging at the level of caspase-3. ${ }^{1}$ Anoikis is induced in cells after their detachment from the extracellular matrix (ECM) switching on apoptotic signaling pathways. ${ }^{2}$ Necrosis, also known as unorganized way of dying or bioenergetic catastrophe, has been recently shown to be 'programmed' under certain conditions. ${ }^{3}$ Type II PCD or autophagic cell death has been observed during embryonic development. ${ }^{4,5}$

Since the first description of autophagy in $1966,{ }^{6}$ numerous studies have described it as a survival mechanism under poor nutritional conditions. It is now clear this process has a dual role. ${ }^{7}$ By contrast, autophagy is a degradative mechanism for long-lived proteins and damaged organelles through the auto-phago-lysosomal pathway and on the other, it provides possibility of self-destruction for cells. ${ }^{4,5,8}$ In Drosophila, autophagy can be hormonally controlled by ecdysone; through inhibition of a class-I phosphatidyl-inositol 3-kinase (PI3K) pathway organs, such as the fat body, are eliminated at the end of larval stage ${ }^{8,9}$ MCF-7 cells can also be induced to undergo autophagy and cell death by treatment with the antiestrogen tamoxifen, which increases the intracellular ceramide level and eliminates the inhibitory effect of class-I PI3K pathway. ${ }^{10}$ Expression of death-associated protein kinase and its death-related protein kinase-1 in MCF-7 and various other cell lines can induce autophagy and caspase-independent cell death. ${ }^{11}$ When caspase-8 was inhibited and the atg7 and beclin-1 expression knocked down by RNA interference, death through autophagy was blocked in mouse L929 cells. ${ }^{12}$ In embryonic fibroblasts with homozygous deletion of both bax and bak, RNA interference against atg5 and beclin could prevent autophagic cell death. ${ }^{13}$

The fate of dead cells depends on their localization within the body. Macrophages acting as professional phagocytes are capable of engulfing apoptotic cells undergoing type I PCD without inducing inflammatory response. ${ }^{14,15}$ Typical examples of this clearance are found during embryonic development when a large number of apoptotic cells are removed ${ }^{16}$ and during clearance of apoptotic granulocytes in inflammation. ${ }^{17}$ Many cells of different origin, including epithelial cells, can act as non-professional phagocytes and engulf apoptotic cells. ${ }^{18,19,20,21}$ The list of key molecular players involved in these phagocytic interactions, often referred to as the 'third synapse', is surprisingly extensive suggesting there are several redundant molecular mechanisms for efficient and fast removal of dying and dead cells. ${ }^{22}$

To our present knowledge the final fate and clearance mechanism of cells dying either through autophagy or by other

\footnotetext{
${ }^{1}$ Departments of Biochemistry and Molecular Biology, Apoptosis and Genomics Research Group of the Hungarian Academy of Sciences, Biophysics and Cell Biology, Research Center for Molecular Medicine, University of Debrecen, Debrecen, Hungary; ${ }^{2}$ Division of Pharmacology, University of Antwerp, Antwerp, Belgium and ${ }^{3}$ Abtl. Institut für Krebsforschung, Medizinische Universität, Wien

*Corresponding author: L Fésüs, Department of Biochemistry and Molecular Biology, University of Debrecen, Medical and Health Science Center, Egyetem ter 1, Life Science Building, POB 6, Debrecen 4010, Hungary. Tel: + 36-52-416-432; Fax: + 36-52-314-989; E-mail: fesus@ indi.biochem.dote.hu

Keywords: autophagy; anoikis; phagocytosis; macrophages; non-professional phagocytes; gene expression

Abbreviations: AV, autophagic vacuoles; CFDA-SE, carboxyfluoresceindiacetatesuccinimidyl ester; CMTMR, 5-(and-6)-(((4-chloromethyl)benzoyl)amino)tetramethylrhodamine; DAPK, death-associated protein kinase; DRP-1, death-related protein kinase-1; FITC, fluorescein isothiocyanate; LC3, light-chain-3; MCSF, macrophage colony stimulating factor; MDC, monodansylcadaverin; PCD, programmed cell death; PI3K, phosphatidyl-inositol 3-kinase; poly-HEMA, poly(2hydroxyethylmethacrylate); PS, phosphatidylserine; PI, propidium iodide; TAM, tamoxifen ([ $\alpha$-(4- $\beta$-N-dimethylaminoethoxy)-phenyl- $\alpha^{\prime}$-ethyl-trans-stilbene $\left.]\right)$; TEM, transmission electron microscopy; TLDA, TaqMan low-density array; TNF, tumor necrosis factor

Received 27.4.06; revised 08.11.06; accepted 21.12.06; Edited by E Baehrecke; published online 16.3.07
} 

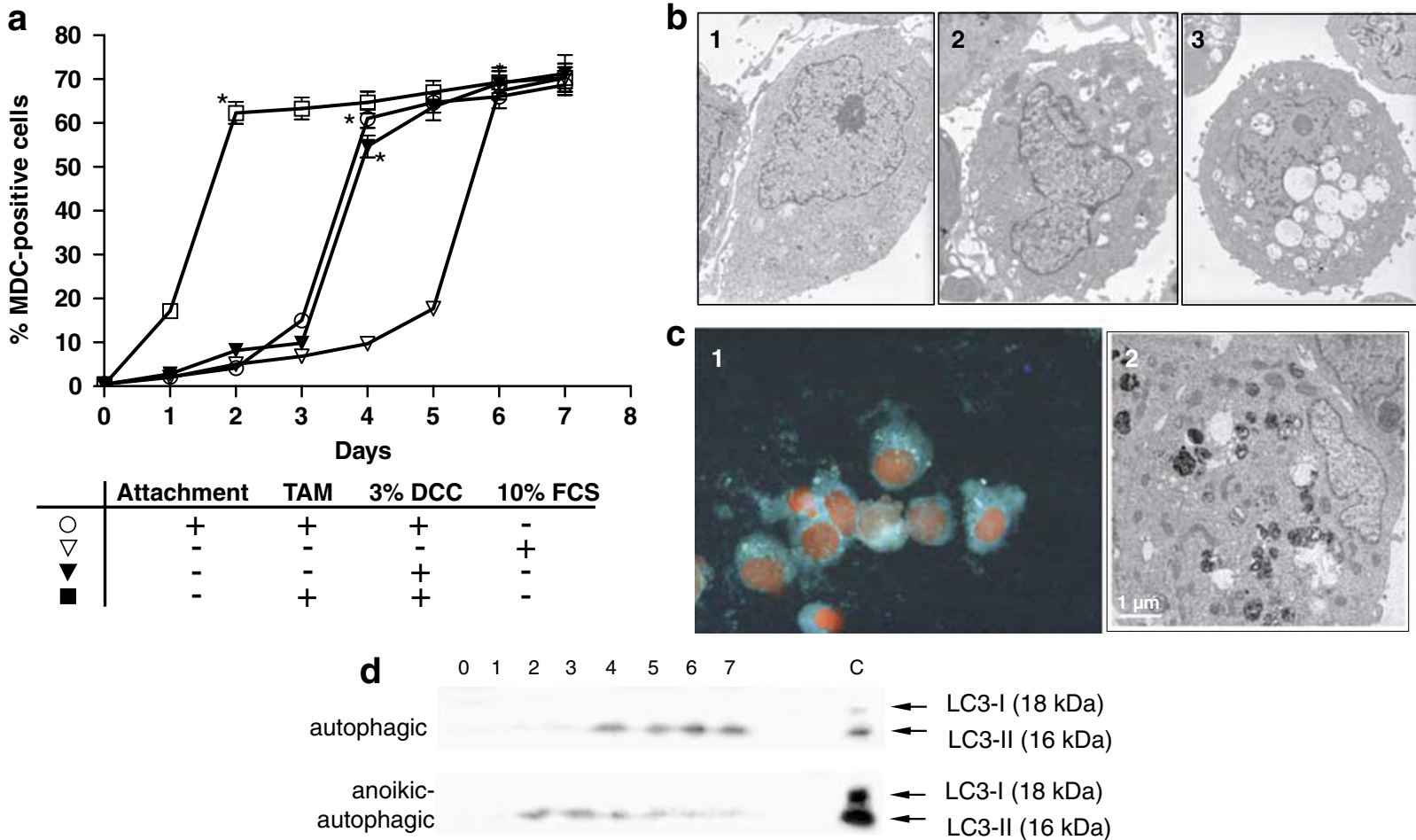

Figure 1 Autophagy in MCF-7 cells following various treatments. (a) Percentage of MCF-7 cells with MDC-positive AVs; $(\bigcirc)$ underwent heavy autophagy by day 4; $(\nabla)$, $(\nabla)$ and $(\square)$ showed shift to autophagy by days 6, 4 and 2, respectively; 1000 cells in each of triplicate cultures were counted; the total number of MDC-positive cells are expressed as percentage of total cells scored. Means of three experiments are shown. Vertical bars indicate s.d.; when not shown, it is smaller than the symbols. (*) time of peaking autophagy assessed by MDC positivity. (b1-3) Transmission electron microscopy of control cells (b1), as well as day 4, attached, 3\% DCC and TAM- treated cells (b2) and day 6 anoikic cells in 10\% FCS (b3), showing numerous double-membraned AVs containing digested materials. (c1) Fluorescent microscopy with MDC/PI and (c2) TEM of day 2, 3\% DCC and TAM-treated anoikic cells. Note the AVs in the cytoplasm (in blue) surrounding the nucleus (in red). (d) Western blot analysis of the LC3 expression in anoikic-autophagic $(\nabla)$ and autophagic cells $(O)$. Positive control $(C)$ was obtained from $\mathrm{C2C12}$ cells undergoing autophagy and showing bands for both LC3-I and LC3-II

mechanisms with associated autophagy have not been clarified. We have initiated a series of experiments, in which type II cell death was induced through autophagy in MCF-7 cells by tamoxifen treatment (de novo autophagy), ${ }^{4}$ and we studied the engulfment of these cells by professional and nonprofessional phagocytes, that is human macrophages and MCF-7 cells, respectively. Furthermore, we studied the clearance of MCF-7 cells showing autophagy following initiation of death through anoikis (anoikic-autophagy), a newly recognized phenomenon described here. We show here that both de novo autophagic and anoikis-derived dying autophagic MCF-7 cells are engulfed by macrophages and MCF-7 cells. Their phagocytosis is executed through distinct mechanisms and low-density gene array studies have revealed that the expression of genes related to the engulfment process is differentially regulated by the two kinds of dying cells.

\section{Results}

Induction of autophagy in MCF-7 cells by tamoxifen treatment and through anoikis. Induction of autophagy, and through that cell death, by 3\% Dulbecco's modified Eagle's medium (DMEM) containing 3\% charcoal-stripped- fetal calf serum (FCS) (DCC) followed by tamoxifen treatment in MCF-7 mammary epithelial cells has been previously described by Bursch et al. ${ }^{4}$ and demonstrated here using both monodansylcadaverin (MDC) uptake into autophagic vacuoles (AVs) and transmission electron microscopy (TEM) to identify autophagic cells. As shown in Figure 1a, the number of MDC-positive de novo autophagic cells peaked at day 4 under such conditions and autophagic vacuolization could be observed by TEM (Figure 1-b2).

Anoikis initiated by detachment of cells from the ECM in vitro has been introduced as a model for studying the mechanism of cell death in the absence of ECM-derived signals in vivo. Our MCF-7 cells underwent anoikis in $10 \%$ FCS of culture when not allowed to attach to the plate. However, we have also observed they showed signs of autophagy at day 6 of incubation: detachment of MCF-7 cells induced by poly(2-hydroxyethylmethacrylate) (poly-HEMA) coated plates resulted in occurrence of AVs as detected by MDC staining (Figure 1a) and TEM (Figure 1-b3). Combining detachment with either $3 \%$ DCC or $3 \%$ DCC + tamoxifen $((\alpha-$ (4- $\beta$ - $N$-dimethylaminoethoxy)-phenyl- $\alpha^{\prime}$-ethyl-trans-stilbene)) (TAM) treatment accelerated the autophagic response to occur 2 days earlier than the time of autophagy in attached cells with the same treatment. All treatment regimens $(3 \%$ DCC + TAM, 10\% FCS + poly-HEMA, 3\% DCC + poly- 

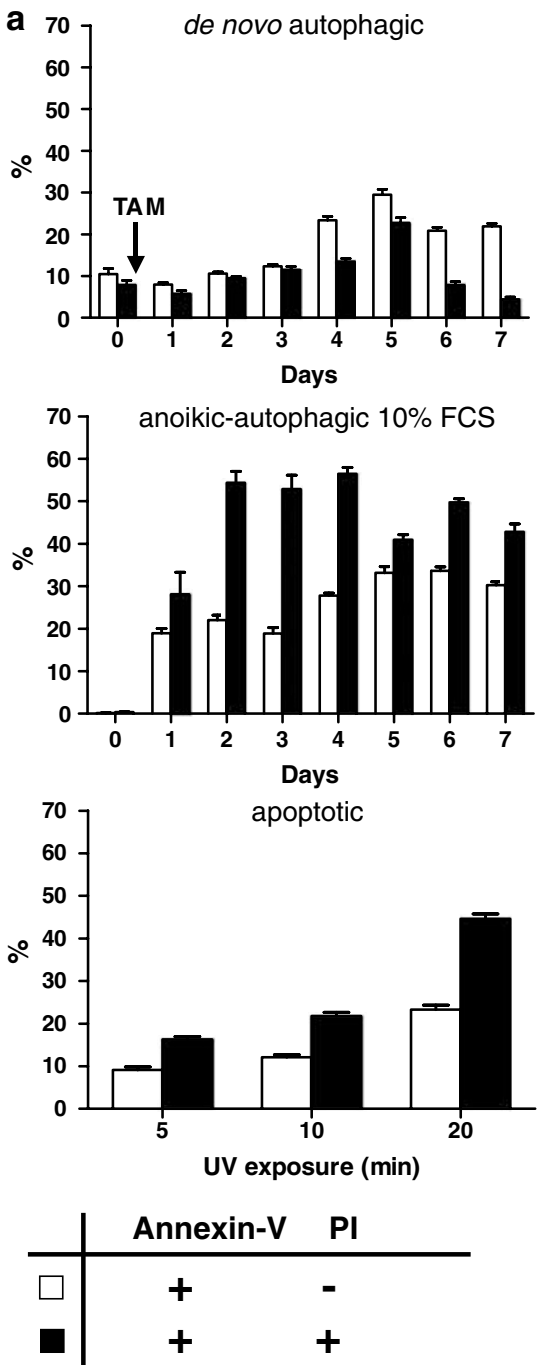
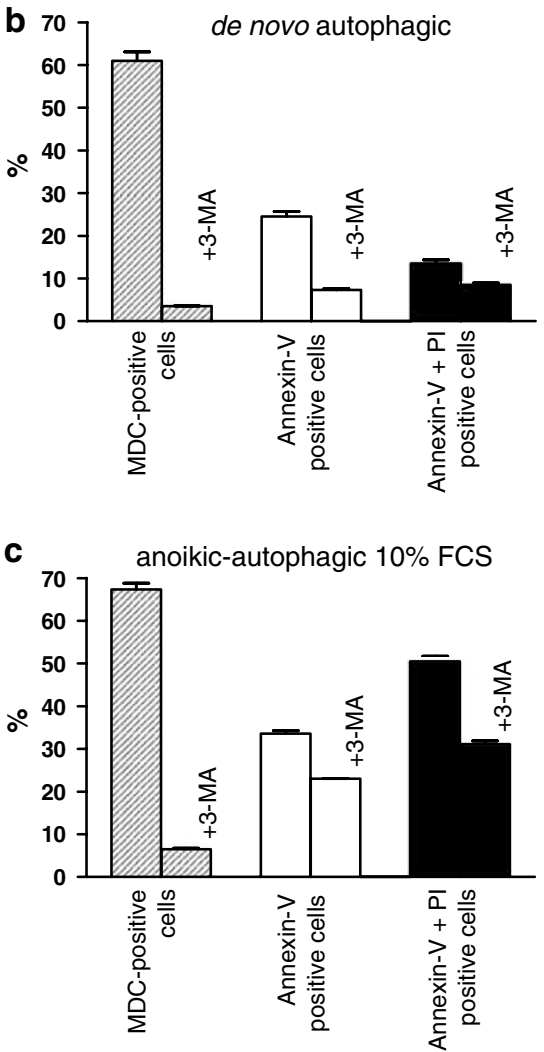

Figure 2 Cell death and the influence of 3-MA in autophagic, anoikic and apoptotic MCF-7 cells. (a) Percent of annexin-V and both annexin-V and PI-positive cells under the shown treatments as assessed by FACS analysis. (b) Effect of $10 \mathrm{mM}$ 3-MA treatment on autophagy and cell death of day 4 autophagic and day 6 anoikic-autophagic cells (c) as assessed by the presence of MDC, annexin-V and/or PI-positive cells. Note that de novo autophagic cells were fed on $3 \%$ DCC for 7 days before the indicated ' 0 ' time point. At this starting point, anoikic-autophagic as well as anoikis-3\% DCC cells with or without TAM showed less than $0.04 \%$ cell death. Means of three experiments are shown. Vertical bars indicate s.d.; when not shown it is smaller than the symbol

HEMA, 3\% DCC + TAM + poly-HEMA) affected the time course but not the maximal degree of the autophagic response (about $70 \%$ of MCF-7 cells were affected in each case, Figure 1a); an example of the MDC-positive dot-like structures representing AVs in the cytoplasm of cells is shown (day 2, 3\% DCC + TAM + poly-HEMA treated MCF-7 cells, Figure 1-c1). Typical absence of chromatin condensation in the nucleus of these cells and numerous AVs with double membranes containing digested materials were also seen by TEM (Figure 1-c2).

Time-dependent development of autophagy was also supported by findings of Western blot analysis of light-chain3 (LC3) expression in case of de novo autophagic (3\% $\mathrm{DCC}+\mathrm{TAM})$ and anoikic-autophagic (10\% FCS + polyHEMA) cells (Figure 1d). In autophagic MCF-7 cells LC3-II (the autophagosomal membrane-bound form of $\mathrm{LC}^{25}$ ) became detectable at day 4 , then increased up to day 7 in parallel with the observed pattern of MDC staining. In the anoikic-autophagic cells, the expression of LC3-II appeared at days 1 and 2 , then showed a decrease from day 4 to day 7 ; this does not necessarily mean that autophagy was downregulated knowing that LC3 may itself undergo degradation by lysosomal enzymes.

Occurrence of cell death in de novo autophagic and anoikis-derived autophagic cells. After peaking of autophagy in de novo autophagic cells at day 4 (3\% DCC + TAM), the number of dying cells peaked at day 5 as assessed by their positivity for annexin- $\mathrm{V}^{+}$or annexin- $\mathrm{V}^{+}$ propidium iodide $(\mathrm{PI})^{+}$(Figure $2 \mathrm{a}$ ). When counted by fluorescence microscopy, more than $95 \%$ of the dying cells were MDC positive at this time point (data not shown) suggesting that autophagy was directly related to cell death. 

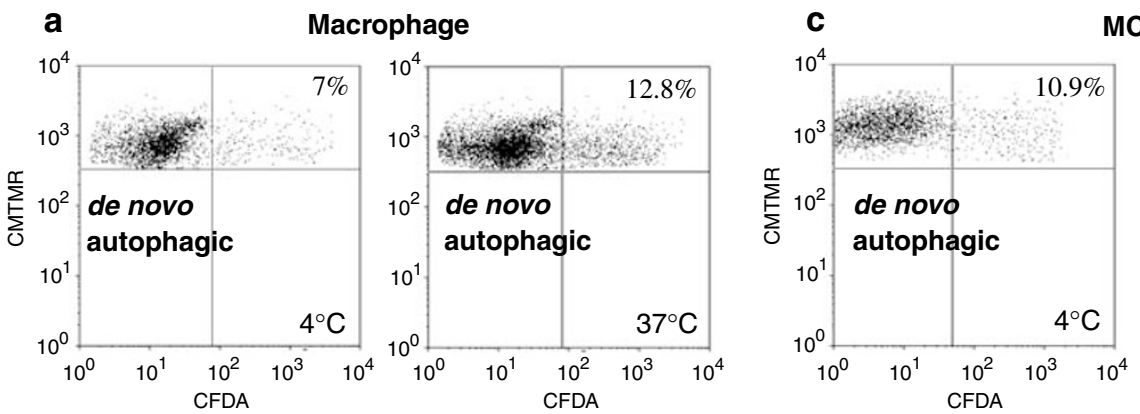

MCF-7
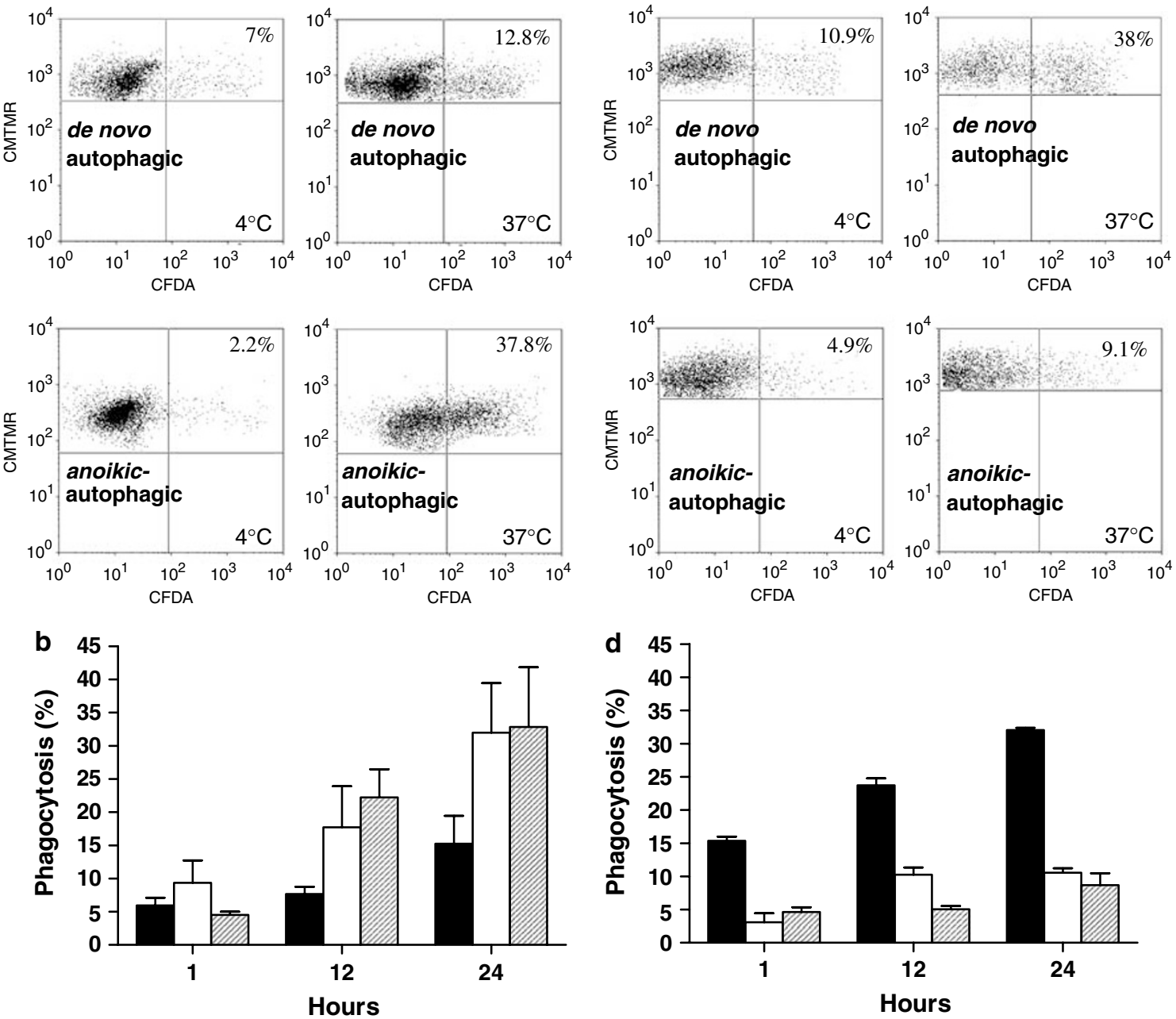

Figure 3 Flow cytometric analysis of the phagocytosis of dying cells. (a) Macrophages and (c) MCF-7 cells stained with CMTMR engulfing either autophagic or anoikicautophagic cells stained with CFDA. The phagocytic assays were performed at $4^{\circ} \mathrm{C}$ at which binding occurs without engulfment, and parallels at $37^{\circ} \mathrm{C}$ at which both binding and engulfment occur. The macrophages that have not phagocytosed are in the right upper left quadrant and the ones that have are in the right upper quadrant; dying cells have been gated out from the lower left and right quadrants. Time of coincubation in each case was $12 \mathrm{~h}$. (b) Macrophages and (d) MCF-7 cells were challenged to engulf $d e$ novo autophagic ( $\mathbf{\square})$, anoikic-autophagic ( $\square$ ), or UV irradiated apoptotic ( $\square)$ MCF-7 cells. Bars represent mean of four independent experiments and s.d.

Inhibition of autophagy in these cells at day 4 by the autophagy inhibitor 3-methyladenine (3-MA) almost completely abolished the MDC-positive staining and led to a significant drop in the number of annexin- $\mathrm{V}^{+}$and annexin$\mathrm{V}^{+} \mathrm{PI}^{+}$cells (Figure $2 b$ ). The percentage of dying cells in anoikic-autophagic cells was twice as much as in de novo autophagy; death occurred earlier and peaked not in association with the peaking of autophagy (Figure 2a). Inhibition of autophagy in these cells at day 6 with 3-MA almost completely abolished the MDC-positive staining as in de novo autophagic cells and led to a decrease in the percentage of annexin- $\mathrm{V}^{+}$or annexin- $\mathrm{V}^{+} \mathrm{PI}^{+}$cells (Figure 2c). For comparison, percentage of annexin- $\mathrm{V}^{+}$or annexin- $\mathrm{V}^{+} \mathrm{PI}^{+}$stained cells following UV-induced apoptosis is also presented (Figure 2a); in this case cell death was not influenced by treatment with 3-MA (not shown).
Both de novo and anoikis-derived dying autophagic cells are engulfed by macrophages and non-dying MCF7 cells. Although phagocytosis of apoptotic and necrotic cells has been extensively studied, no data are available how cells dying through autophagy or those in which death is accompanied with autophagy are removed from tissues. Our macrophages and MCF-7 cells could engulf dying de novo autophagic or anoikic-autophagic cells with increasing number of phagocytes containing cell corpses over a $24 \mathrm{~h}$ time period (Figure 3a-d). As flow cytometric analysis shows, compared to phagocytosis of UV-irradiated apoptotic MCF-7 cells, macrophages engulfed anoikicautophagic cells more efficiently, than they did de novo autophagic dying cells (Figure $3 \mathrm{~b}$ and $\mathrm{d}$ ): at $24 \mathrm{~h}$ of coincubation about $32 \%$ of them contained anoikis-derived dead cells, whereas only $15 \%$ of them showed phagocytosis of dying de novo autophagic cells. MCF-7 cells, however, 

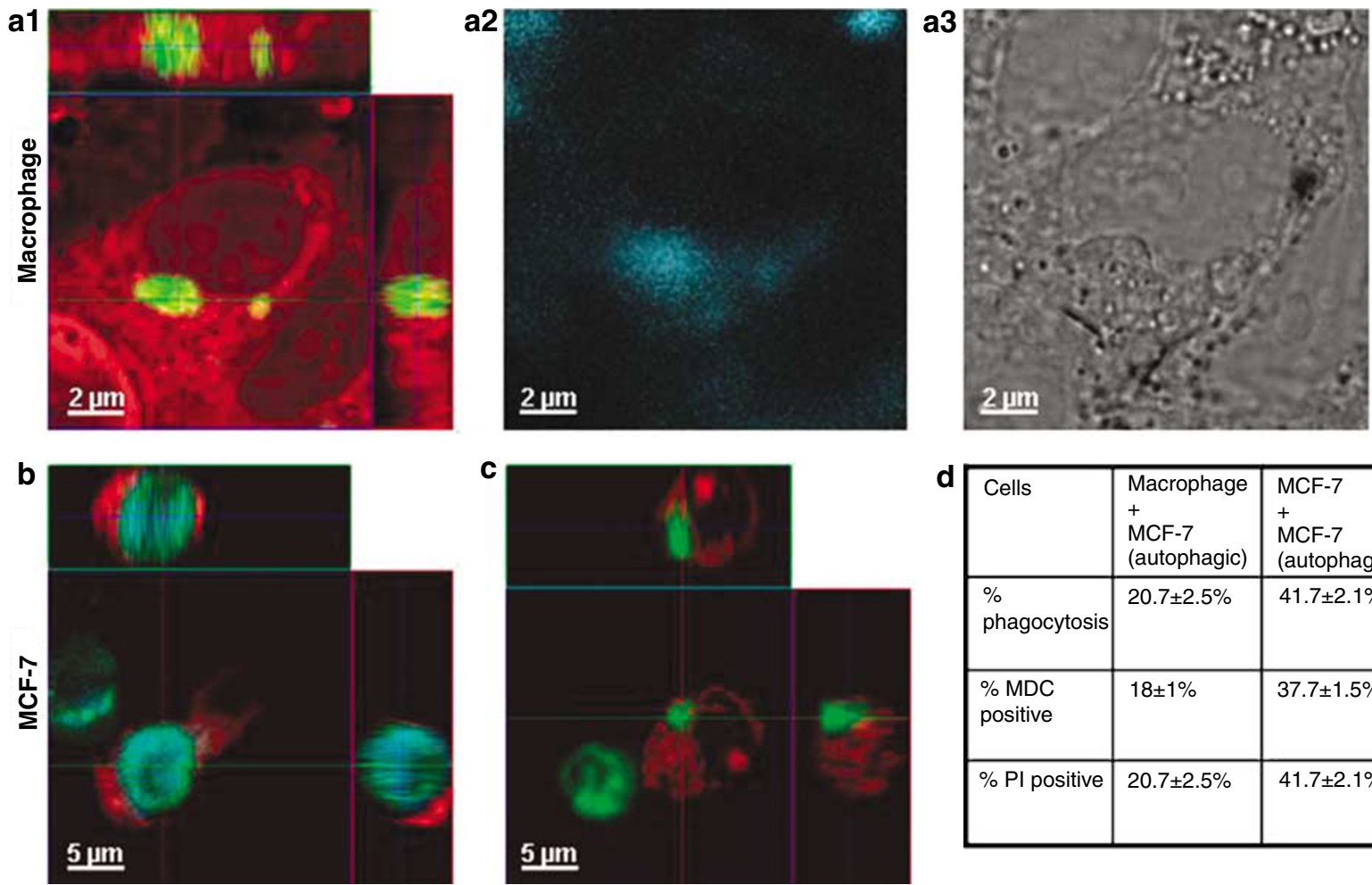

\begin{tabular}{|l|l|l|}
\hline Cells & $\begin{array}{l}\text { Macrophage } \\
+ \\
\text { MCF-7 } \\
\text { (autophagic) }\end{array}$ & $\begin{array}{l}\text { MCF-7 } \\
+ \\
\text { MCF-7 } \\
\text { (autophagic) }\end{array}$ \\
\hline $\begin{array}{l}\% \\
\text { phagocytosis }\end{array}$ & $20.7 \pm 2.5 \%$ & $41.7 \pm 2.1 \%$ \\
\hline $\begin{array}{l}\% \text { MDC } \\
\text { positive }\end{array}$ & $18 \pm 1 \%$ & $37.7 \pm 1.5 \%$ \\
\hline$\%$ PI positive & $20.7 \pm 2.5 \%$ & $41.7 \pm 2.1 \%$ \\
\hline
\end{tabular}

Figure 4 Detection of the phagocytosis of autophagic cells by confocal microscopy. (a1-3) Macrophage stained with CMTMR (red) that had engulfed de novo autophagic cell stained with CFDA (green) and MDC (blue) are co-localized. (a3) Phase-contrast image of the same cells as in (a1-2). Non-dying MCF-7 cells stained with CMTMR (red) that have engulfed either de novo autophagic stained with both MCD (blue) and CFDA (green) (b) or anoikic-autophagic cells (c) stained with CFDA (green). Note the orthogonal views of phagocytosis in (b) and (c) as well as the yet uneaten cells (green) in the proximity. (d) Percentage of both CFDA and MDC-positive cells being engulfed by CMTMR-positive cells in (a) and (b) as counted under a fluorescent microscope. In all cases, the time of co-incubation of dying and engulfing cells was $24 \mathrm{~h}$. Means of three separate experiments are presented with their s.d.

engulfed dying de novo autophagic cells much more efficiently than either anoikic-autophagic or apoptotic ones, reaching an average phagocytosis frequency of $32 \%$ at the same time point.

To confirm the results obtained by flow cytometry the uptake of dying autophagic cells was also investigated by fluorescence confocal microscopy using a newly developed three-color technique. The latter was specifically designed for detecting colocalization of engulfed autophagic MCF-7 cells stained with both carboxyfluoresceindiacetate (CFDA) (green) and MDC (blue) within the 5-(and-6)-(((4chloromethyl)benzoyl)amino)tetramethylrhodamine (CMTMR) (red) colored phagocytosing cells (Figure $4 a-c)$. Confocal microscopy confirmed the intracytoplasmic localization of the engulfed de novo autophagic or anoikic-autophagic dead cells being double stained with CFDA and MDC within either macrophages or non-dying MCF-7 cells. Under the experimental conditions used, usually one non-dying MCF-7 cell acting as 'eater' engulfed one autophagic or anoikic-autophagic cell. Counting under the microscope determined that an average of $21 \%$ of macrophages and $42 \%$ of engulfing MCF-7 cells contained cell corpses of de novo autophagic origin after $24 \mathrm{~h}$ coincubation (Figure $4 \mathrm{c}$ ). Almost all of the engulfed cells were autophagic (87-90\% positive for MDC staining) and all of the eaten cells could be stained by $\mathrm{PI}$, that is, by definition they were dying autophagic cells.

\section{Autophagic component of cell death and appearance of phosphatidylserine on dead cells differentially influence phagocytosis. Inhibition of autophagy by 3-MA, applied 2 days before peaking of autophagy, and harvesting these cells for the phagocytic assay, almost completely abolished the engulfment of de novo autophagic cells by both macrophages and MCF-7 cells. On the contrary, treatment with 3-MA did not affect significantly the engulfment of anoikic-autophagic cells (Figure $5 a$ and b). Treatment of the dying de novo autophagic and anoikic-autophagic cells with recombinant annexin- $V$ before and throughout the phagocytic assay that is blocking phosphatidylserine (PS) on the surface of dying cells, could inhibit significantly only engulfment by non-dying MCF-7 cells and not by macrophages. The inset in Figure 5 summarizes the differential effects of 3-MA and annexin- $V$ on the phagocytosis of the two kinds of autophagic cells by the two types of engulfing cells.}

Expression profile of apopto-phagocytic genes in macrophages and MCF-7 cells. Quantitative gene expression analysis of macrophages and MCF-7 cells was 


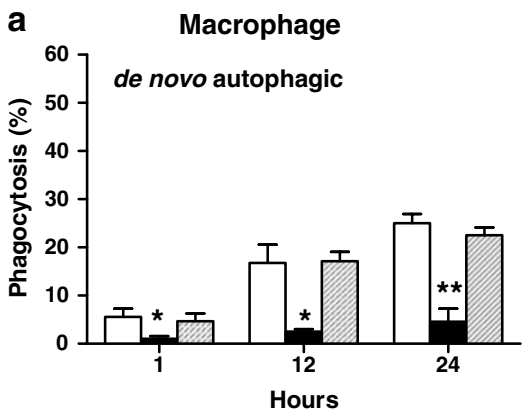

\begin{tabular}{l|l|c|c} 
Eater & Treatment & $\begin{array}{c}\text { De novo } \\
\text { Autophagic }\end{array}$ & $\begin{array}{c}\text { Anoikic- } \\
\text { autophagic }\end{array}$ \\
\hline \multirow{2}{*}{ MФ } & 3-MA & + & - \\
\cline { 2 - 4 } & Annexin-V & - & - \\
\hline \multirow{2}{*}{ MCF-7 } & 3-MA & + & - \\
\cline { 2 - 4 } & Annexin-V & + & +
\end{tabular}
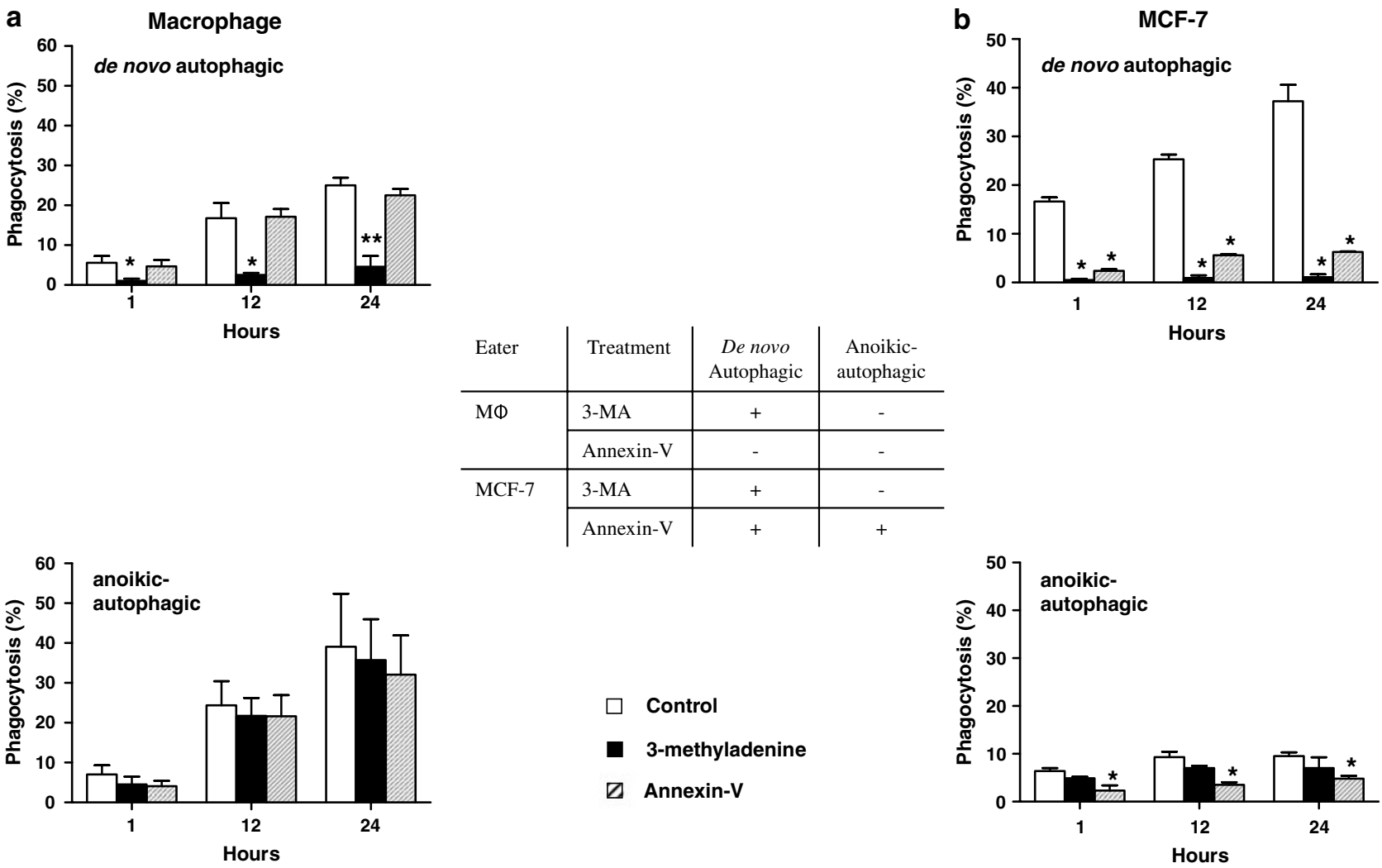

Figure 5 Phagocytic capacity of (a) macrophages and (b) MCF-7 cells when challenged to engulf de novo autophagic or anoikic-autophagic MCF-7 cells under uninhibited conditions $(\square)$, when the autophagic and anoikic-autophagic cells were pretreated by 3-MA 2 days before autophagy peaked ( $\boldsymbol{\square}$ ) and when phagocytosis was carried out in the presence of recombinant annexin-V $10 \mu \mathrm{g}$ per $10^{5}$ cells $(\mathbb{Z})$. The inset shows when 3-MA and recombinant annexin-V influence uptake of dying cells by the two types of phagocytes. Bars represent mean values of three independent experiments and their s.d. ${ }^{*} P<0.05 ;{ }^{\star \star} P<0.01$ using Student's $t$-test

carried out to gain insight into the potential molecular mechanisms mediating phagocytosis by these cells. The studied genes have been selected to cover most of the so far described molecular elements, which may participate in the clearance of dead cells. The data from the gene expression profiling clearly show that both macrophages and MCF-7 cells are well equipped for phagocytosis of dying cells. In macrophages, almost all studied genes of the various functional groups were expressed and the following ones have very high basal expression levels: calreticulin, the scavenger receptors CD68 and MSR1, the low-density lipoprotein-related protein 1 (LRP1), integrins $\alpha_{x}$ and $\beta_{2}$ (phagocytosis receptors), annexin A5, the C1QA-bridging molecule and transforming growth factor $-\beta$ (Table 1). Interestingly, many of the studied and expressed phagocytic genes were also expressed in MCF-7 cells. The exceptions, with very low expression levels in comparison to macrophages, include the $\mathrm{C} 1 \mathrm{Q}$ receptor $1, \mathrm{MSR} 1$, the oxidized low-density lipoprotein 1 receptor (OLR1), integrin $\alpha_{x}$ among the phagocytosis receptors, the adenosine receptor A3 (ADORA3), the formyl peptide receptor like 1, the bridging and surface molecules C1QA and ICAM3, respectively, the inflammatory regulators caspase 1 and 5 , NALP12 and the cytokines interleukin-6 (IL)-6, IL-10, IL-12B, IL-23A. Calreticulin, annexin A5 and calpain 1 showed highbasal expression in these cells.
Clearance of autophagic and anoikic-autophagic cells initiates distinct transcriptional responses in macrophages and MCF-7 cells. Gene expression profiling of macrophages and MCF-7 cells while they were consuming dying cells as compared with their resting state was done at $12 \mathrm{~h}$. The engulfment of de novo autophagic cells elicited different response in the two types of phagocytes. In macrophages, the asialoglycoprotein receptor 1 (ASGR1), ADORA2A, the bridging molecule PTX3, phospholipase IPLA2 $\gamma$, the engulfment molecules GULP1 (which was not expressed in the resting cells) and RAC1, the cytokines IL-6, IL-12B, IL-23A and tumor necrosis factor $(T N F-\alpha)$ were induced. ADORA3, the plateletactivating factor receptor, the bridging and surface molecules C3 and ICAM 3, respectively, the inflammatory regulators BIRC1 and NALP12 were downregulated in macrophages eating de novo autophagic cells. MCF-7 cells showed increased expression of annexin-1 and the engulfment molecule ELMO1. Both phagocytes upregulated OLR1 and IL-6 to a significant degree in response to the dying de novo autophagic cells.

Macrophages eating anoikic-autophagic cells upregulated C1Q receptor 1, ADORA1 and ADORA2A, (whereas downregulating several phagocytosis receptor and surface molecules including CD68, MSR1, LRP1, integrins, ADORA3, annexin-1, ICAM3 and the platelet/endothelial cell adhesion 
molecule), the bridging molecules C4B and MFGE8 (whereas downregulating $\mathrm{C} 2$ and $\mathrm{C} 3$ ), the signaling molecule protein kinase 2, the engulfment protein RAC1 (whereas downregulating ELMO 1), DNASE1 (whereas downregulating DNASE2), the proinflammatory caspase 5 (whereas down- regulating NALP12) and the cytokine IL-6. MCF-7 cells responded to anoikic-autophagic cells by upregulating the AXL receptor tyrosine kinase.

The question may arise whether the elevated mRNA levels observed in engulfing cells could come from the eaten cells.

Table 1 Gene expression levels in macrophages and MCF-7 cells and their changes during phagocytosis

\begin{tabular}{|c|c|c|c|c|c|c|c|c|c|}
\hline \multirow[t]{2}{*}{ Category } & \multirow[t]{2}{*}{ Gene description } & \multirow{2}{*}{$\begin{array}{c}\text { Macrophage } \\
\text { Control }\end{array}$} & \multicolumn{2}{|c|}{$\begin{array}{c}\text { Phagocytosing } \\
\text { macrophage }\end{array}$} & \multirow{2}{*}{$\begin{array}{l}\text { MCF-7 } \\
\text { Control }\end{array}$} & \multicolumn{2}{|c|}{$\begin{array}{c}\text { Phagocytosing } \\
\text { MCF-7 }\end{array}$} & \multicolumn{2}{|c|}{ Dying MCF-7 } \\
\hline & & & 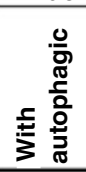 & 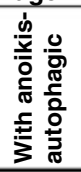 & & 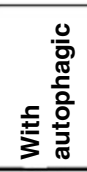 & 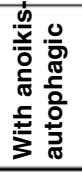 & $\begin{array}{l}\frac{0}{0} \\
\frac{0}{0} \\
\frac{0}{0} \\
\frac{0}{7} \\
\frac{7}{4}\end{array}$ & 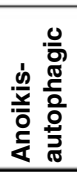 \\
\hline \multirow{16}{*}{ 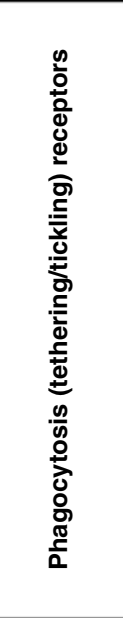 } & ASGR1 & & +++ & & & & & +++ & +++ \\
\hline & MERTK $^{1}$ & & & & & & & -- & \\
\hline & TYRO3 $^{1}$ & & & & & & & & - \\
\hline & C1QR1 & & & + & & & & & \\
\hline & CALR & & & & & & & & \\
\hline & CD14 & & & & & & & & \\
\hline & $\mathrm{CD}^{2} \mathrm{8}^{2}$ & & & - & & & & & + \\
\hline & MSR1 $^{2}$ & & & -- & & & & & \\
\hline & SCARB $^{2}{ }^{2}$ (CD36) & & & & & & & & \\
\hline & ITGAM $^{3}$ & & & -- & & & & - & --- \\
\hline & ITGAV $^{3}$ & & & & & & & & \\
\hline & ITGAX ${ }^{3}$ & & & -- & & & & +++ & +++ \\
\hline & ITGB2 $^{3}$ & & & - & & & & - & - \\
\hline & ITGB3 $^{3}$ & & & & & & & & -- \\
\hline & ITGB5 $^{3}$ & & & & & & & & \\
\hline & LRP1 & & & - & & & & & \\
\hline \multirow{14}{*}{ 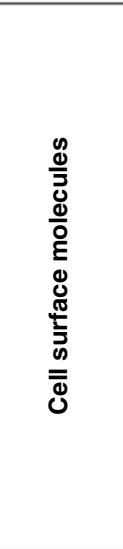 } & ABCA1 & & & & & & & - & --- \\
\hline & ADORA1 & & & ++ & & & & & - \\
\hline & ADORA2A & & +++ & +++ & & & & & \\
\hline & ADORA3 & & -- & -- & & & & & \\
\hline & ANXA1 & & & - & & + & & & - \\
\hline & ANXA5 & & & & & & & & \\
\hline & CD47 & & & & & & & & - \\
\hline & ICAM3 & & - & -- & & & & +++ & \\
\hline & IL4R & & & & & & & & \\
\hline & PECAM1 & & & -- & & & & & \\
\hline & PTAFR & & - & & & & & - & - \\
\hline & PTDSR & & & & & & & & \\
\hline & PTGER2 & & & & & & & - & --- \\
\hline & TGFBR1 & & & & & & & & \\
\hline \multirow{13}{*}{ 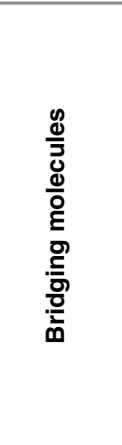 } & APOH & & & & & & & & \\
\hline & C1QA & & & & & & & & \\
\hline & C2 & & & -- & & & & --- & \\
\hline & C3 & & - & - & & & & - & - \\
\hline & C4B & & & + & & & & & \\
\hline & CRP & & & & & & & & \\
\hline & EDIL3 & & & & & & & & \\
\hline & GAS6 & & & & & & & & - \\
\hline & MFGE8 & & & + & & & & & \\
\hline & PROS1 & & & & & & & & - \\
\hline & PTX3 & & +++ & & & & & & --- \\
\hline & RAP1A & & & & & & & & \\
\hline & THBS1 & & & & & & & & -- \\
\hline
\end{tabular}




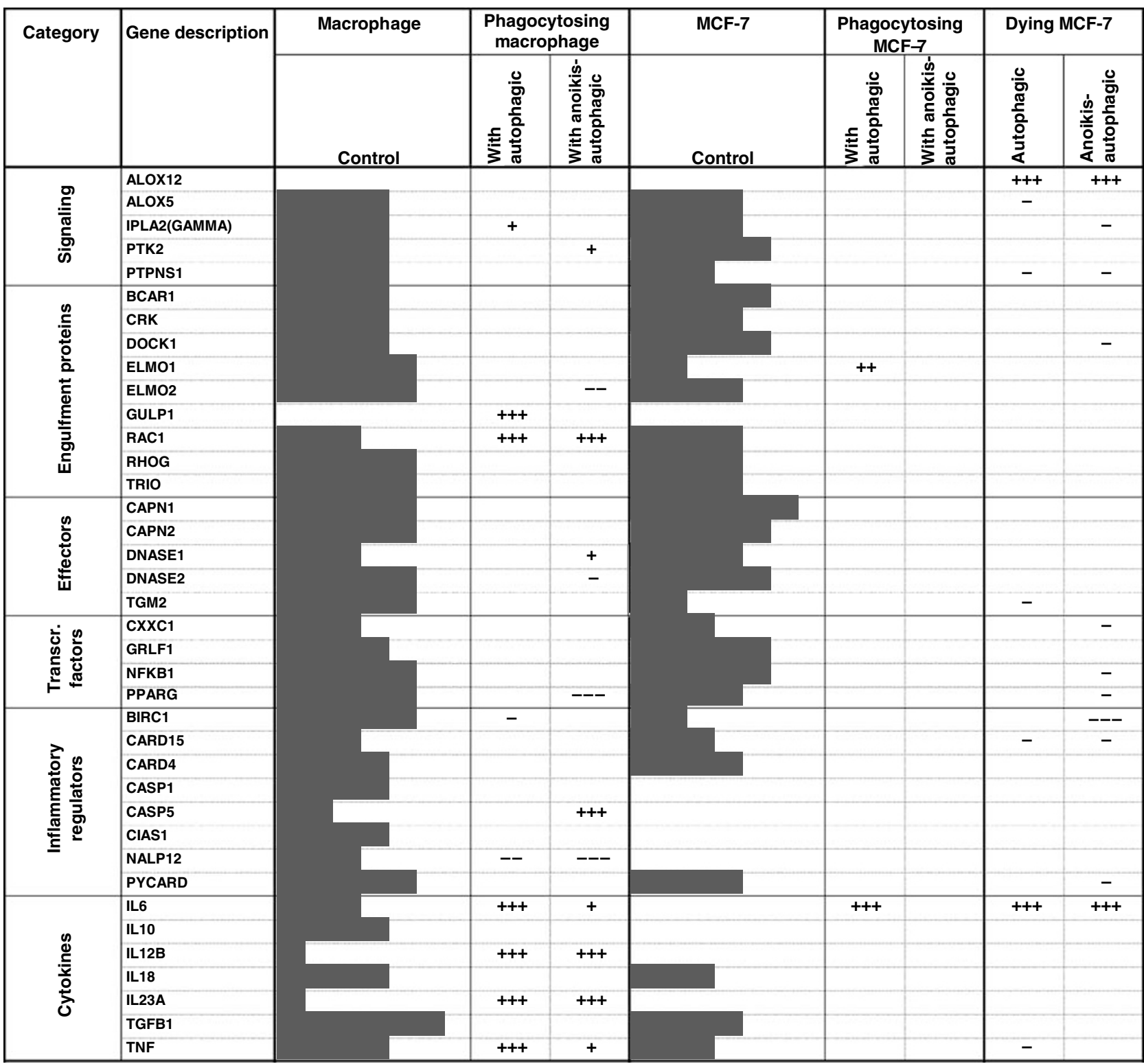

Relative expression levels:
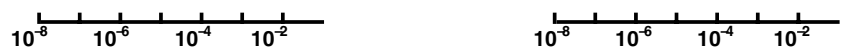

The basal expression levels were determined in 3 independent biological samples and each was analyzed in two parallel runs in which each gene had two technical replicates. Based on the average of the obtained result (the variation coefficient was less than $20 \%$ in each case), the relative expression of a particular gene in macrophages and MCF-7 cells is indicated. The increments of the horizontal bars represent one order of magnitude higher range of relative expression (related to $18 \mathrm{~S}$ RNA) and the size of the bar at each gene indicates into which range the actual expression data (average of three repeated experiments) fall. In case of analyzing gene expression changes during phagocytosis, change of mRNA level was considered significant when it repeatedly (at least in two biological samples, both analyzed in two parallel runs each with two replicates per gene) exceeded 2.5 times the average expression level of the controls, either increasing or decreasing (+ or -$)$. It is also indicated in the table when the change of expression was more than 5.0 times (++ or --$)$ and 10 times (+++ or --- as compared to controls. The nomenclature of the genes studied is in compliance with the HUGO classification; ${ }^{1}$ Mer tyrosine kinase family, ${ }^{2}$ scavanger receptors, ${ }^{3}$ integrins

This is very unlikely, as the overlapping upregulated genes in two different types of phagocytes eating the same kind of dead cells do not show systematic 'cross contamination'. In addition, analysis of the gene expression changes in de novo autophagic (day 4) and anoikic-autophagic (day 6) cells as compared to untreated MCF-7 cells clearly shows the genes being upregulated in either macrophages or engulfing MCF-7 cells are not upregulated in the two kinds of dying cells (Table 1). The exceptions are ASGR1 and IL-6 in both kinds of dying cells, and OLR1 in de novo autophagic cells. However, 
other upregulated genes in dying cells (ITGAX, ICAM3, ALOX12) do not have increased levels in the engulfing phagocytes.

\section{Discussion}

Insufficient clearance of dying cells may lead to inflammation and autoimmune diseases. Molecular mechanisms participating in the clearance of apoptotic cells by macrophages have been described in detail and, to a lesser extent, this can be said about non-professional phagocytes. ${ }^{14,18,19,26,27}$ It has been suggested that autophagy as a mechanism of cell death may have been developed because in some forms of PCD the availability of engulfing cells is insufficient for the clearance of dead cells and autophagy has been evoked for elimination of excess cells by their own lysosomes. ${ }^{13}$ In the present study we clearly demonstrate this is not the case: autophagic MCF-7 cells of different origin are recognized and eaten by both differentiated macrophages and non-dying MCF-7 cells. As almost all engulfed cells were $\mathrm{MDC}^{+}$and all were $\mathrm{PI}^{+}$, we may conclude that the eaten cells were dead or dying autophagic cells, and not cells that use autophagy to survive.

An equally important question is whether the engulfed MCF-7 cells died through autophagy (i.e. autophagy killed the cells) or by apoptosis during which autophagy was switched on, but did not contribute to killing of the cells. Only a few examples are available to prove that autophagy is an important death pathway in cells with intact apoptosis machinery. ${ }^{28}$ On the basis of several indirect evidences it has been proposed that active cell death is induced through autophagy in tamoxifen-treated MCF-7 cells; ${ }^{5}$ one of the evidences is the inhibition of both autophagy and cell death by 3-MA, a compound that can specifically block the sequestration step in macro-autophagocytosis inhibiting class III phosphatidylinositol-kinase activity. As in our experiments 3MA also inhibited macrophage and MCF-7 cell-mediated phagocytosis of dying de novo autophagic cells, it can be suggested that molecular events linked to autophagy and death are involved in specific surface changes, which are important in subsequent recognition and elimination of these dying cells.

We have also described here a novel way of inducing autophagy through initiation of anoikis, which could facilitate autophagy even in de novo autophagic cells. In case of anoikis, cells actually die through apoptosis with coincident autophagy, which, has no causative role in the death process itself. How anoikis-initiated death response switches on autophagy and why anoikis accelerates tamoxifeninduced autophagy certainly requires further investigation. Examples for the induction of apoptosis with the help of autophagy regulators, such as the p53-induced dram and the calpain-generated cleavage product of atg5, have been described. ${ }^{29,30}$ It is also possible that elements of the apoptosis machinery, while killing cells, may initiate autophagy to fasten self-elimination even before phagocytosis; in our case loss of integrin-dependent survival pathways may lead to induction of death effectors' which in turn converge onto mediators of autophagy, such as Atg5, Atg7 and beclin-1. Nevertheless, inhibition of autophagy by 3-MA in these anoikic-autophagic cells have resulted in less inhibition of cell death than in de novo autophagic cells and, most importantly, did not have an effect on the engulfment of these anoikic-autophagic cells by either of the phagocytic cell types. Therefore, we have described clearance of autophagic dying cells in two kinds of paradigm; one in which cells died mainly through autophagy, generating specific cell surface changes for recognition and engulfment, and another, where cell death occurred with concomitant autophagy, which is not the main inducer of death and does not contribute to specific cell surface changes for removal by phagocytes.

Our results show that non-professional phagocytes, the non-dying MCF-7 cells, are much more efficient in taking up de novo autophagic cells than anoikic-autophagic ones; that is, they can recognize the difference between death through autophagy and death associated with autophagy. Dying cells present on their surface several 'eat-me' signals facilitating their engulfment, one such being externalized PS. Recombinant annexin-V, which binds PS exposed on the surface of dying cells, could block the engulfment of dying de novo autophagic cells by MCF-7 cells (Figure $5 a$ and b); this clearly suggests that whatever specific changes are induced by autophagy on the surface of these dying cells - making them edible for MCF-7 cells (see inhibition by 3-MA) - is directly or indirectly linked to PS. On the other hand, uptake of de novo autophagic cells by macrophages could not be inhibited by recombinant annexin- $\mathrm{V}$, indicating that PS-independent cell surface changes are induced in cells dying through autophagy. To our present knowledge, no specific cell surface changes have been described that would make autophagic cells edible for phagocytes. A handful of proteins have been shown to undergo internalization from the plasma membrane following the induction of autophagy. ${ }^{31,32}$ Recently, calreticulin appearing on the surface of apoptotic cells was found to initiate their clearance acting together with PS for achieving optimal phagocytic clearance of cells. ${ }^{33}$ Changing carbohydrate composition of glycoproteins ${ }^{34}$ and exposure of DNA on dying cells ${ }^{35}$ have been proposed as alternative mechanisms to PS for recognition of dead cells. Further studies are required to determine whether these alternative 'eat me' signals or others are exposed on the surface of cells dying through autophagy.

Autophagy in cells dying through anoikis did not contribute to clearance of these cells by either MCF-7 cells or macrophages. However, the uptake of these cells by MCF-7 was inhibited when PS was covered on the cell surface. The anoikic-autophagic cells were very efficiently eaten by macrophages in a PS-independent manner. As this was not related to the appearance of autophagy (could not be inhibited by 3-MA), the PS-independent recognition and signaling system in this case must be different from the one utilized by cells dying through autophagy.

Molecular elements used for the clearance of dead cells are highly conserved and strongly interrelated with components of the innate immune system. ${ }^{15}$ It has been suggested that different surface receptors on the phagocytes are involved in tethering (recognition and binding of cell corpses) and tickling (internalization and activation of downstream signaling) processes, leading via at least two major pathways to activation of Rac, which is obligatory for uptake of dead 
cells. $^{36}$ In case of PS recognition, at least one tethering (integrins or integrin-associated proteins, e.g. CD36) and one internalization receptor (bridging molecule MFGE8) are needed for efficient clearance. Tickling is mediated by Gas or protein $S$ through one of the tyrosine kinase receptors (MERTK, AXL or TYRO3) leading to activation of Rac engaging TRIO, RhoG, DOCK180, Crkll and ELMO. Exposed calreticulin is recognized by collectins and ficolins (such as C1QA, PTX) serving as bridging molecules; then the opsonized dead cells are bound to phagocytosis receptors on the surface, including calreticulin in conjunction with LRP1 (which signals to Rac through GULP); as an alternative, thrombospondin is the bridging molecule and integrin $\alpha_{v}$ or calreticulin serve as receptors. We have used a low-density gene array approach to learn which of the above and other previously described molecular participants in the clearance mechanisms are expressed in the two types of phagocytic cells.

As discussed above, MCF-7 cells used mainly the PS recognition and signaling pathway for phagocytosis of dying cells. Indeed, various elements of this pathway are expressed by this cell type at significant levels, including the bridging molecules MFGE8, protein $S$ and Gas, the integrin and CD36 tethering receptors, the tickling tyrosine kinase receptors AXL, MERTK and TYRO3, and all the engulfment proteins required for Rac activation (TRIO, RhoG, DOCK180, Crkll and ELMO) through this pathway. It is very likely the expressed complement factors and scavenger receptors also contribute to the efficient uptake of dying cells. It is remarkable that the expression of none of the studied genes showed a decrease during the engulfment of either kind of dying cells. The more efficient uptake of de novo autophagic cells as compared with anoikic-autophagic ones may be related to the specific changes on the surface or the inside of the engulfed dying cells inducing distinct transcriptional responses, such as upregulation of OLR1, ANXA1 and ELMO1. On the other hand, induction of $A X L$ may be linked to the uptake of anoikic-autophagic cell corpses in a PSdependent way.

In macrophages, the molecular elements of the PS recognition and signaling pathway are also highly expressed; one may assume that it is utilized for engulfment of both kinds of autophagic dying cells under normal circumstances. Our gene array data show, however, that the calreticulin-mediated pathway of dead cell clearance is also available for efficient phagocytosis of de novo autophagic cells, and this may explain why phagocytosis of dying autophagic cells is not blocked when PS is covered on their surface. Calreticulin is highly expressed in both the dying and phagocytic cells and may become exposed on the surface; C1QA and LRP1 mRNA are at high concentrations in macrophages; PTX and GULP are specifically induced during uptake of this kind of dying cells, in conjunction with the strong induction of Rac expression. Macrophages can engulf anoikic-autophagic dying cells in a PS-independent way more efficiently than de novo ones, but the calreticulin-C1Q-LRP-GULP pathway is not available because GULP is not induced by the anoikicautophagic cells (see the gene expression profile in Table 1). Again, the difference in phagocytosis efficiency may be related to specific changes on the surface of anoikic- autophagic cells leading to utilization of alternative pathways in macrophages, such as those which involve the highly expressed scavenger receptors, the specifically induced C4B and C1QR1, the signaling molecules PTK2 and DNASE1. Interestingly, macrophages eating anoikic-autophagic dying cells are the ones showing most significant downregulation of several phagocytosis genes; it is possible that while the engulfing cells are engaged in the phagocytosis process, the engulfment genes are downregulated in the non-phagocytic population.

Our gene array profiling of engulfing macrophages has revealed surprising induction of the proinflammatory cytokine genes IL- 6 , TNF- $\alpha$, IL-12B and IL-23B by both kinds of dying cells. In the case of anoikic autophagy this may be explained by the presence of late apoptotic cells, which have been shown to be proinflammatory, ${ }^{37}$ in high proportion at day 6 of anoikis (see percent of annexin- $\mathrm{V}^{+} \mathrm{PI}^{+}$cells in Figure 2a). Regarding cells dying through autophagy, they may expose autophagy-related pro-inflammatory signals on their surface; this may have significance when autophagic death occurs in tumor cells and the inflammatory response can promote tumor growth. ${ }^{38}$ It has been suggested that expressed PS on dying cells has a major function in the generation of an antiinflammatory effect, whereas engagement of calreticulin with collectins stimulate pro-inflammatory mediator production. ${ }^{36}$ As molecular elements of the calreticulin-dependent recognition and engulfment pathway were induced in macrophages engulfing de novo autophagic cells, it is possible that signaling through this pathway participates in the induction of proinflammatory cytokine production. The pro-inflammatory response of macrophages to dying autophagic cells may be also connected to the observed induction of adenosine receptors, particularly ADORA2A in the engulfing cells. ADORA2A is a potent regulator of macrophage functions, including Fc receptor-mediated phagocytosis and pattern recognition receptor-mediated cytokine production. ${ }^{39} \mathrm{De}$ tailed studies are in progress in our laboratory to clarify the molecular mechanism and general implication of cytokine induction in macrophages.

\section{Materials and Methods}

Cell culture and treatments. The list of compounds used throughout the experiments can be found in the Supplementary file. MCF-7 human breast cancer cells were kindly provided by Dr W Bursch, Medizinische Universität Wien, Austria; culture conditions were described in detail previously. ${ }^{5}$ Briefly, cells were grown as a monolayer in DMEM supplemented with $10 \%$ FCS, L-glutamine $(300 \mathrm{mg} / \mathrm{l})$ and penicillin/streptomycin antibiotics at $37^{\circ} \mathrm{C}$ in an atmosphere of $5 \% \mathrm{CO}_{2}$. Seven days before beginning an experiment cells were plated at density of $7.5 \times 10^{3} / \mathrm{cm}^{2}$ in DCC according to Bardon et al. ${ }^{23}$ Twenty-four hours later the cells were treated with freshly prepared TAM in dimethyl sulfoxide/ethanol $(1: 1, \mathrm{v}: \mathrm{v})$ added directly to the medium. For the induction of anoikis, cells were plated on poly-HEMA covered dishes over a 7 day period in either $10 \% \mathrm{FCS}$ or $3 \%$ DCC with or without TAM (i.e. $10 \%$ FCS + poly-HEMA, and 3\% DCC + poly-HEMA, 3\% DCC + TAM + polyHEMA). Apoptosis was induced by UV irradiation $-5,10$ and $20 \mathrm{~min}, 45 \mathrm{~mJ}$ $\left(\mathrm{cm}^{2} \mathrm{~min}\right)$ - and the cells were left to die for $8 \mathrm{~h}$ before harvesting.

Assays of cell death and autophagy. Cell death was assessed by the Annexin-V-fluorescein isothio-cyanate Apoptosis Detection Kit (MBL, Woburn, MA, USA) according to manufacturer's recommendations; proportion of stained Annexin- $\mathrm{V}^{+}$and Annexin- $\mathrm{V}^{+} \mathrm{PI}^{+}$cells was determined by fluorescence activated cell sorter (FACS) analysis on BD Bioscience flow cytometer. Autophagy was assessed by detection of AVs with MDC according to the 
method of Biederbick et al. ${ }^{24}$ and described in more detail in the Supplementary file. Whenever inhibition of autophagy was carried out with 3-MA, the treatment preceded peaking of autophagy in 2 days.

Electron microscopy. Samples were fixed in $0.1 \mathrm{M}$. sodium cacodylatebuffered, $\mathrm{pH} 7.4$ and $2.5 \%$ glutaraldehyde solution for $2 \mathrm{~h}$ and then rinsed (three times, $10 \mathrm{~min}$ ) in $0.1 \mathrm{M}$ sodium cacodylate buffer, $\mathrm{pH} 7.4$ and $7.5 \%$ saccharose and postfixed in $1 \% \mathrm{OsO}_{4}$ solution for $1 \mathrm{~h}$. After dehydration in an ethanol gradient $(70 \%$ ethanol (20 min), 96\% ethanol (20 min), 100\% ethanol (two times, $20 \mathrm{~min})$ ), samples were embedded in Durcupan ACM. Ultrathin sections were stained with uranyl acetate and lead citrate. Sections were examined in a Philips CM 10 microscope (Philips Electronic Instruments, Mahwah, NJ, USA) at $80 \mathrm{kV}$.

Antibodies and immunoblotting. Anti-LC3 polyclonal antibody was prepared in rats by Eurogentec (Seraing, Belgium, see Supplementary file). Cell lysates were separated on NuPAGE 12\% Bis-Tris polyacrylamide gel (Invitrogen, Carlsbad, CA, USA) and transferred to Immobilon-P Transfer Membrane (Millipore, Bedford, MA, USA; pore size $0.45 \mu \mathrm{m})$. Membranes were blocked in Tris-buffered saline containing $0.05 \%$ Tween- 20 (TBS-T) and $5 \%$ nonfat dry milk (BioRad) for $1 \mathrm{~h}$, probed overnight at $4{ }^{\circ} \mathrm{C}$ with primary rat anti-LC3 polyclonal antibody in TBS-T containing $1 \%$ nonfat dry milk and incubated for $1 \mathrm{~h}$ with rabbit antirat peroxidaseconjugated secondary antibody (DAKO, Glostrup, Denmark) at room temperature. Peroxidase activity was detected with SuperSignal West Femto Maximum Sensitivity Chemiluminescent Substrate (Pierce, Rockford, IL, USA) using a Lumi-Imager (Roche Diagnostics, Mannheim, Germany).

Phagocytosis assay. Human monocytes were isolated from 'buffy coats' of healthy blood donors on Ficoll-Paque Plus (Amersham Biosciences) gradient and magnetic separation using CD14 human microbeads (Miltenyi Biotec, Auburn, CA, USA). Human macrophages were obtained through a 5-day differentiation using $5 \mathrm{ng} / \mathrm{ml}$ macrophage colony-stimulating factor. Non-dying MCF-7 cells acting as phagocytes were plated in serum-free medium $24 \mathrm{~h}$ before phagocytosis. Dying cells were fed to engulfing cells when in their culture autophagy peaked: at day 4 for de novo autophagic and day 6 for anoikic-autophagic cells. Inhibition with $10 \mu \mathrm{g}$ recombinant annexin- $\mathrm{V}$ was carried on $10^{5}$ dying cells $(30 \mathrm{~min}$ before phagocytosis assay, $37^{\circ} \mathrm{C}$ ) and maintained throughout the assay. In addition, MCF-7 cells UV irradiated for $20 \mathrm{~min}$ and turning apoptotic $8 \mathrm{~h}$ after irradiation were used for engulfment. The phagocytes, macrophages and non-dying MCF-7 cells, were stained with $7.5 \mu \mathrm{M}$ CMTMR for 16 and $24 \mathrm{~h}$, respectively, before starting the assay. Accordingly, the cells to be engulfed were stained with $12.5 \mu \mathrm{M}$ CFDA for 16 or $24 \mathrm{~h}$ before the phagocytosis and washed twice in phosphate-buffered saline (PBS) before being added to the phagocytes. The ratio of phagocytes and cells to be engulfed was set at 1:5. The phagocytosis assay started when the cells to be engulfed were added to the appropriate phagocytes and kept together for either 1 , 12 or $24 \mathrm{~h}$. The assay was carried out at either $4^{\circ} \mathrm{C}$ when phagocytes bind but do not engulf dying cells, and at $37^{\circ} \mathrm{C}$ when phagocytes bind and/or engulf them. The whole-cell mixture was collected by scraping the cells, centrifuging, washing twice in PBS and fixing in 1\% PBS-buffered paraformaldehyde (pH 7.4). The net phagocytosis rate was determined by FACS analysis as percent phagocytic cells that have engulfed (positive for both CMTMR and CFDA) at $37^{\circ} \mathrm{C}$ minus the observed percent of double-positive cells at $4^{\circ} \mathrm{C}$.

RNA preparation and TaqMan real-time RT-PCR. Total cellular RNA was isolated from human monocyte-derived macrophages as well as from MCF-7 cells using TRIzol Reagent (Invitrogen Life Technologies) at the indicated time point of the phagocytic assay after washing away non-engulfed dead cells thoroughly. Pre-designed, factory-loaded 384- well TaqMan low-density array (Applied Biosystems, Foster City, CA, USA) was used to determine the level of expression of genes grouped and listed in Table 1. Two replicates per target gene and two parallels per biological sample were carried out. Expression levels of target genes were normalized to 18S rRNA as endogenous control. Gene expression values were calculated based on the $\Delta \Delta C_{t}$ method, where one sample was designated as calibrator, through which all other samples were analyzed. $\Delta C_{t}$ represents the threshold cycle $\left(C_{t}\right)$ of the target minus that of $18 \mathrm{~S}$ rRNA and $\Delta \Delta C$ represents the $\Delta C_{t}$ of each target minus that of the calibrator. Relative quantities ( $R Q$ or fold changes) were determined using the equation where relative quantity equals $2^{-\Delta \Delta C_{t}}$ (average of three repeated experiments).
Acknowledgements. This study was supported by grants from the Hungarian National Research Fund (OTKA TO43083, TS44798), National Research and Development Office (NKFP 1A/008/04) and from EU (QLK3-CT-2002 02017). Special thanks to Dr Zsuzsa Szondy for helpful discussions.

1. Lavrik IN, Golks A, Krammer PH. Caspases: pharmacological manipulation of cell death. $J$ Clin Invest 2005; 115: 2665-2672.

2. Gilmore AP. Anoikis. Cell Death Differ 2005; 12 (Suppl 2): 1473-1477.

3. Edinger AL, Thompson CB. Death by design: apoptosis, necrosis and autophagy. Curr Opin Cell Biol 2004; 16: 663-669.

4. Bursch W, Hochegger K, Torok L, Marian B, Ellinger A, Hermann RS. Autophagic and apoptotic types of programmed cell death exhibit different fates of cytoskeletal filaments. J Cell Sci 2000; 113: 1189-1198

5. Bursch W, Ellinger A, Kienzl H, Torok L, Pandey S, Sikorska M et al. Active cell death induced by the anti-estrogens tamoxifen and $\mathrm{ICl} 164384$ in human mammary carcinoma cells (MCF-7) in culture: the role of autophagy. Carcinogenesis 1996; 17: 1595-1607.

6. De Duve C, Wattiaux R. Functions of lysosomes. Annu Rev Physiol 1966; 28: 435-492.

7. Codogno P, Meijer AJ. Autophagy and signaling: their role in cell survival and cell death. Cell Death Differ 2005; 12 (Suppl 2): 1509-1518.

8. Baehrecke EH. Autophagic programmed cell death in Drosophila. Cell Death Differ 2003; 10: $940-945$

9. Baehrecke EH. Autophagy: dual roles in life and death? Nat Rev Mol Cell Biol 2005; 6: 505-510.

10. Scarlatti F, Bauvy C, Ventruti A, Sala G, Cluzeaud F, Vandewalle A et al. Ceramidemediated macroautophagy involves inhibition of protein kinase $B$ and up-regulation of beclin 1. J Biol Chem 2004; 279: 18384-18391.

11. Inbal B, Bialik S, Sabanay I, Shani G, Kimchi A. DAP kinase and DRP-1 mediate membrane blebbling and the formation of autophagic vesicles during programmed cell death. J Cell Biol 2002; 157: 455-468.

12. Yu L, Alva A, Su H, Dutt P, Freundt E, Welsh $S$ et al. Regulation of an ATG7-beclin 1 program of autophagic cell death by caspase-8. Science 2004; 304: 1500-1502.

13. Shimizu S, Kanaseki T, Mizushima N, Mizuta T, Arakawa-Kobayashi S, Thompson CB et al. Role of $\mathrm{Bcl}-2$ family proteins in a non-apoptotic programmed cell death dependent on autophagy genes. Nat Cell Biol 2004; 6: 1221-1228.

14. Grimsley C, Ravichandran KS. Cues for apoptotic cell engulfment: eat-me, don't eat-me and come-get-me signals. Trends Cell Biol 2003; 13: 648-656.

15. Savill J, Dransfield I, Gregory C, Haslett C. A blast from the past: clearance of apoptotic cells regulates immune responses. Nat Rev Immunol 2002; 2: 965-975.

16. Jacobson MD, Weil M, Raff MC. Programmed cell death in animal development. Cell 1997; 88: 347-354

17. Savill JS, Wyllie AH, Henson JE, Walport MJ, Henson PM, Haslett C. Macrophage phagocytosis of aging neutrophils in inflammation. Programmed cell death in the neutrophil leads to its recognition by macrophages. J Clin Invest 1989; 83: 865-875.

18. Monks J, Rosner D, Geske FJ, Lehman L, Hanson L, Neville MC et al. Epithelial cells as phagocytes: apoptotic epithelial cells are engulfed by mammary alveolar epithelial cells and repress inflammatory mediator release. Cell Death Differ 2005; 12: 107-114.

19. Fadok VA, Bratton DL, Henson PM. Phagocyte receptors for apoptotic cells: recognition, uptake and consequences. J Clin Invest 2001; 108: 957-962.

20. Thompson CB. Apoptosis in the pathogenesis and treatment of disease. Science 1995; 267: 56

21. Henson PM, Bratton DL, Fadok VA. Apoptotic cell removal. Curr Biol 2001; 11: 795-805.

22. Majai G, Petrovski G, Fesus L. Inflammation and the apopto-phagocytic system. Immunol Lett 2006; 104: 94-101.

23. Gill PG, Vignon F, Bardon S, Derocq D, Rochefort H. Difference between R5020 and the antiprogestin RU486 in antiproliferative effects on human breast cancer cells. Breast Cancer Res Treat 1987; 10: 37-45.

24. Biederbick A, Kern HF, Elsasser HP. Monodansylcadaverine (MDC) is a specific in vivo marker for autophagic vacuoles. Eur J Cell Biol 1995; 66: 3-14.

25. Kabeya Y, Mizushima N, Ueno T. LC3, a mammalian homologue of yeast Apg8p, is localized in autophagosome membranes after processing. EMBO J 2000; 19: 5720-5728.

26. Fadok VA, Bratton DL, Rose DM, Pearson A, Ezekewitz RA, Henson PM. A receptor for phosphatidylserine-specific clearance of apoptotic cells. Nature 2000; 405: 85-90.

27. Krieser RJ, White K. Engulfment mechanism of apoptotic cells. Curr Opin Cell Biol 2002; 14: 734-738.

28. Reef S, Zalckvar E, Shifman O, Bialik S, Sabanay H, Oren M et al. A short mitochondrial form of p19ARF induces autophagy and caspase-independent cell death. Mol Cell 2006; 22: $463-475$.

29. Crighton D, Wilkinson S, O'Prey J, Syed N, Smith P, Harrison PR et al. DRAM, a p53induced modulator of autophagy, is critical for apoptosis. Cell 2006; 126: 30-32.

30. Yousefi S, Perozzo R, Schmid I, Ziemiecki A, Schaffner T, Scapozza L et al. Calpainmediated cleavage of Atg5 switches autophagy to apoptosis. Nat Cell Biol 2006; 8: 1124-1132.

31. Tagawa Y, Yamamoto A, Yoshimori T, Masaki R, Omori K, Himeno M et al. A $60 \mathrm{kDa}$ plasma membrane protein changes its localization to autophagosome and autolysosome membranes during induction of autophagy in rat hepatoma cell line, H-4-II-E cells. Cell Struct Funct 1999; 24: 59-70. 
32. Baricault L, Fransen JA, Garcia M, Sapin C, Codogno P, Ginsel LA et al. Rapid sequestration of DPP IV/CD26 and other cell surface proteins in an autophagic-like compartment in Caco-2 cells treated with forskolin. J Cell Sci 1995; 108: 2109-2121.

33. Gardai SJ, McPhillips KA, Frasch SC, Janssen WJ, Starefeldt A, Murphy-Ullrich JE et al. Cell-surface calreticulin initiates clearance of viable or apoptotic cells through transactivation of LRP on the phagocyte. Cell 2005; 123: 321-334.

34. Dini L. Recognizing death: liver phagocytosis of apoptotic cells. Eur J Histochem 2000; 44: 217-227.

35. Palaniyar N, Nadesalingam J, Clark H, Shih MJ, Dodds AW, Reid KB. Nucleic acid is a novel ligand for innate, immune pattern recognition collectins surfactant proteins A and D and mannose-binding lectin. J Biol Chem 2004; 279: 32728-32736.
36. Henson PM, Hume DA. Apoptotic cell removal in development and tissue homeostasis. Trends Immunol 2006; 27: 244-250.

37. Patel VA, Longacre A, Hsiao K, Fan H, Meng F, Mitchell JE et al. Apoptotic cells, at all stages of the death process, trigger characteristic signaling events that are divergent from and dominant over those triggered by necrotic cells: implications for the delayed clearance model of autoimmunity. J Biol Chem 2006; 281: 4663-4670.

38. Degenhardt K, Mathew R, Beaudoin B, Bray K, Anderson D, Chen G et al. Autophagy promotes tumor cell survival and restricts necrosis, inflammation, and tumorigenesis. Cancer Cell 2006; 10: 51-64.

39. Hasko G, Pacher P, Deitch EA, Vizi ES. Shaping of monocyte and macrophage function by adenosine receptors. Pharmacol Ther 2006; 113: 264-275.

Supplementary Information accompanies the paper on Cell Death and Differentiation website (http://www.nature.com/cdd) 